\title{
Evaluating Exchange Rate Models Based on Rational Expectations versus Imperfect Knowledge Economics
}

\author{
Ismail Onur Baycan $^{1}$ \\ ${ }^{1}$ Department of Economics, Anadolu University, Eskisehir, Turkey \\ Correspondence: Ismail Onur Baycan, Department of Economics, Anadolu University, Eskisehir, Turkey.
}

Received: August 28, 2015

Accepted: September 30, $2015 \quad$ Online Published: October 12, 2015

doi:10.5430/ijfr.v6n4p187

URL: http://dx.doi.org/10.5430/ijfr.v6n4p187

\begin{abstract}
Understanding the factors that explain the causes of exchange rate swings has been one of the major concerns in the international finance field. Conventional models, which utilize Rational Expectation Hypothesis (REH), are frequently tested and employed in the international finance literature to explain the exchange rate fluctuations. On the other hand, Imperfect Knowledge Economics (IKE) has recently been developed as an alternative approach to understand the same concerns on the exchange rate swings. This paper, for the first time, employs the Lakatosian framework of Scientific Research Programs (SRPs) to evaluate the main theoretical contributions of these models on the exchange rate fluctuations. First, the study evaluates the novel facts that are associated with each of the Lakatosian protective belts for both of these SRPs. In addition, the study evaluates the empirical evidence of each SRP related to these novel facts, and argues whether or not these are theoretically and empirically progressive in the Lakatosian framework.
\end{abstract}

Keywords: exchange rate models, rational expectations, imperfect knowledge economics, Lakatosian scientific research programs

\section{Introduction}

Economists have tried to have a better understanding about the floating exchange rate regimes since the collapse of the Breton Woods system in 1973. Understanding the factors that explain the causes of exchange rate swings have been the major concern in the international finance field. Conventional models, which utilize Rational Expectation Hypothesis (REH), are frequently tested and employed in the international finance literature. On the other hand, Imperfect Knowledge Economics (IKE) has recently been developed as an alternative approach to understand the same concerns about the exchange rate swings. This paper, for the first time, employs the framework of Lakatosian Methodology of Scientific Research Programs (MSRPs) to evaluate the main theoretical contributions of these models on the exchange rate fluctuations.

There are four main features about the currency fluctuations that both conventional REH and IKE models aim to explain. These features can shortly be summarized as follows: First, they undergo long swings away and towards the historical benchmark levels. Second, these swings are bounded, which means that they eventually trend right through the historical benchmarks. Third, they pass through the historical benchmark. Four, these swings are uneven in an irregular sense. Both REH and IKE models examine these features with different point of views to reveal the characteristics of these swings.

Utilizing Lakatosian methodology for the evolution of the scientific research programs (SRPs), this paper explains the ability of these two different theoretical models on generating novel facts. The study compares the REH and IKE based models and analyze whether or not they are empirically and theoretically progressive in terms of Lakatos's framework. The paper first discusses the evolution of the REH and IKE models. Besides, the study identifies the novel facts associated with each of the models and evaluates the success of their predictions that have been empirically explained.

The paper is organized as follows: Section two argues the main points of the REH and IKE based exchange rate theories and their predictions. Section three discusses Lakatos's idea of MSRPs. Section four employs Lakatos's methodology of scientific research programs to evaluate the models of REH and IKE of exchange rate swings by presenting and discussing the empirical evidence on explaining the swings on the exchange rates. Section five 
concludes.

\section{REH and IKE Based Models of Exchange Rate Swings}

Contemporary studies heavily adopt a set of a priori assumptions to characterize how rational individuals make decisions. These studies utilize REH for their centerpiece view of rationality. The exchange rate models based on REH rule out the possibility that market participants' forecasting strategies actually play an autonomous role in driving the aggregate outcomes.

Frydman and Goldberg (2007) argue that contemporary models suffer from insuperable epistemological flaws. Consequently, macroeconomists often find gross inconsistencies compared to the theory when they confront their models with time-series data. They address a common source for these inconsistencies that results from the REH based exchange rate models. They discuss that contemporary economists fully prespecify the causal mechanism that underpins the change in real-world markets and propose an alternative approach to deal with these inconsistencies, which is called the Imperfect Knowledge Economics. This approach has different set of assumptions to avoid the problem of generating sharp predictions. They explain how acknowledging the limits of individual knowledge may enable economists to shed new light on the basic features of the observed market outcomes. They investigate how these new models of exchange rate swings that utilize IKE is superior for explaining the fluctuations and risk in asset markets.

By employing REH based models, contemporary economists ignore the importance of incorporating the fact that participants in real-world markets do not stick to one and only one forecasting strategy. Therefore, the REH based models do not include the crucial fact that people alter the way that they make decisions. On the other hand, IKE based models take into account the social contexts and particularly economic policies that change over time, at least intermittently. On the contrary, to determine the relationship how individual decisions and the social context may change over time, the REH based models use invariant and mechanical approaches. As a result, the REH based theories fully prespecify the set of possible structures that represent the outcomes.

\section{Lakatosian Methodology of Scientific Research Programs}

Lakatos is widely known with his methodological thinking that combines Popper's critical interpretation of falsification with the revolutionary historical approach of Kuhn. Kuhn's description of science mostly focuses on the historical side of science. Popper, on the other hand, argues that the new theories, which open new eras, may well not be consistent with highly supported older theories.

Lakatos develops a new conception of science that would make it empirically rational, which is called the Methodology of Scientific Research Programs (MSRPs). MSRPs distinguish a series of interrelated theories within a paradigm or conceptual framework. This methodology reconciles the arguments of Popper that promotes rational scientific improvements and Kuhn's argument of being reliable with the historical data. Hands (2001) interprets this idea as a kind of jujitsu move that allowed Lakatos to turn the Kuhnian rival's attack into a success for the Popperian philosophical program. Popper's falsification suggests that scientists put forward theories and that nature 'shouts no' in the form of an inconsistent observation. Harvey (1978) emphasizes Popper's argument that it is irrational for scientists to maintain their theories in the face of Nature's rejection. However, Lakatos concludes that, "It is not that we propose a theory and nature may shout no rather we propose a maze of theories and nature may shout inconsistent"(Lakatos, 1970, p.130).

Serving this idea, Lakatos discusses two key terms in terms of this framework, namely, a "hard core" and a "protective belt". With the hard core, Lakatos mentions the basic assumptions that don't change in research programs. As Blaug (1992) highlights, hard core distinguishes different SRPs that has properties for the theories that are important for all membership in the SPR. Therefore, these hard cores are the assumptions which share the basic common ideas. Because rejecting this hard core is equivalent with leaving the main related scientific idea, a scientist always attempts to protect the hard core.

With the second key term, the protecting belt, Lakatos points out the assumptions and ideas that can be modified in time. The scientists involved in a program aim to protect the theoretical core from falsification attempts behind a protective belt of auxiliary hypotheses. Popper generally considers such kind of measures as 'ad hoc'. Lakatos, on the other hand, suggests that adjusting and developing a protective belt is not necessarily a bad thing for a research program. Lakatosian approach does not argue whether a hypothesis is true or false, but instead, it aims to figure out whether a scientific research program is better than the other ones. This point of view considers to compare the programs to have a common basis to prefer one to the others.

Consequently, a MSRP can be called progressive while its rivals are degenerating. A progressive research program 
expands and includes its novel facts. With the discovery of stunning novel facts, it is marked by its properties of growth and development of new experimental techniques with more precise predictions. On the other hand, a degenerating research program has continuous failures of making scientific progress. Contrary to the progressive research programs, it is marked by lack of growth, or growth of the protective belt that does not lead to any further novel facts. Therefore, it is possible to observe science as a rational progress of choice that comes with evidence.

The terminology of Lakatos's MSRP is widely accepted by practitioners in different particular SRPs. It follows that novel facts are needed for a progressive scientific research program, and Lakatos's approach argues that research projects are better to explain the scientific progress. Moreover, when there are shifts, these shifts are the research program revisions all within the same paradigm.

\section{An Appraisal of REH versus IKE Based Exchange Rate Models Using the Lakatosian SRPs}

Different analyses on examining the exchange rate swings institute different SRPs in the Lakatosian framework. The contemporary exchange rate models that utilize REH versus the others that employ IKE constitute different Lakatosian SRP protective belts. Using this Lakatosian analysis, it is possible to argue whether or not REH and IKE type of exchange rate models are progressive explaining the fundamental characteristics of the exchange rate swings. To do so, the study first evaluates the novel facts, which are associated with each SRP's protective belts. Moreover, the study evaluates the empirical evidence related to these novel facts. As discussed in the previous section, a SRP can be defined as progressive only if the theory is both theoretically and empirically progressive. Therefore, the study first compares the predictions of both the models based on REH and IKE to find out whether they are theoretically progressive or not, and discusses how well the predictions of REH and IKE models match up with the reality.

To explain the characteristics of exchange rate swings, the contemporary models employing REH impose quantitative and mechanical conditions, which enforce sharp predictions for these models. The other SRP of the study, IKE, imposes qualitative conditions without imposing sharp predictions. According to the first Lakatosian SRP models that utilize REH, the summation for complete decisions of individuals is not systematically wrong. Many of the contemporary models, including the largely known Flexible Price and Sticky Price Models, impose REH. These models utilize the Uncovered Interest rate Parity (UIP) as an equilibrium condition in the foreign exchange markets. The UIP condition imposes that the exchange rate adjusts to ensure the expected return on holding domestic assets equals the expected return on holding foreign assets. This causes this particular SRP to have very sharp and strong assumptions. It assumes that the market never changes the way it forecasts, and it forecasts with the variables the economist deems are relevant. According to this view, the market interprets these variables exactly how the economist does, meaning that the market forecasts the future relevant variables same as the economist. Therefore, everybody holds exactly the same expectations at every point in time. This SRP defines this argument rational, where nobody makes systematic forecasting errors. Market participants predict the prices correctly on average by assuming that knowledge is fixed at each point in time. This means that the distribution of the error term is the same at every point in time in the exchange rate models that imposes REH. As a result, there is an overarching forecasting strategy that REH uses today, which never changes between now and the eternity. Therefore, REH assumes that the conditional probability distribution is the same at every point in time.

Theoretically, the SRP representing the exchange rate models based on REH generates only one novel fact. This only novel fact is given by the sticky price models. According to the sticky price models, as exchange rate does all the adjusting, prices are sticky and cannot freely jump in the short run. This explains the deviations of the swings from the benchmark level for the short term. However, this does not explain why these swings do not get back to their historical benchmark levels for a long time. But, nevertheless, this can be seen as the only novel fact of this Lakatosian SRP. Therefore, at least we can emphasize that the SRP employing the REH has at least one theoretical novel fact that is associated with the long deviations of the exchange rate swings.

In the Lakatosian framework, it is only a necessary condition to have at least one theoretically novel fact for evaluating the properties of a particular SRP. Additionally, to indicate whether or not the SRPs are progressive in terms of Lakatosian perspectives, one also needs to evaluate if these theories are empirically progressive or not. Therefore, in Lakatos's framework, the empirical prediction of a theory also matters for the analysis. Following the Lakatosian framework, the study considers an important question from Lakatos's point of view: whether do predictions of the exchange rate theories match up with the real life empirics?

In terms of real life empirics about explaining the basic properties of exchange rate swings, the SRP representing the conventional models using REH documents very poor results. The leading researches in the field, including Rogoff (1996), mention that the real life results that these REH based models document is quite embarrassing. The empirical 
failures of the REH based conventional exchange rate models can be examined under three anomalies, which are often argued in the literature, including the studies of Dornbusch et al (1983), Evans et al (2005), Frankel (1982), Frankel et al. (1987).

First of these anomalies is known as the Purchasing Power Parity Puzzle. Empirical studies suggest that the reversion of the real exchange rate to parity is too slow and too persistence in real exchange rates. In this manner, Rogoff (1996) argues a "consensus view" of a half-life between 3 to 5 years. This is way too long to be compatible with what the theory proposes. Other alternative views, including the market power, pricing to market, and non-traded local costs are simply not enough to explain both high persistence and high volatility differences. Engel (1996) discusses that most of the puzzle originates in traded goods, where presumably alternative explanations are hardest. Furthermore, Chari, Kehoe, and McGratten (2002) report that these models with plausible rigidities cannot reproduce this type of real exchange rate persistence.

Second of these well-known anomalies is the Exchange Rate Disconnect Puzzle. This anomaly stands for the relationship between the conventional models and the way that they understand how macroeconomic fundamentals and rational behavior affect the exchange rates. In this contemporary approach SRP, since the conventional exchange-rate theorists model individual behavior and aggregate outcomes with fully predetermined representations, the outcome fails to find an overarching relationship between the exchange rates and macroeconomic fundamentals. Therefore, this SRP of the conventional economists concludes that swings in exchange rates that are away from benchmark levels are unconnected to the changes in these macroeconomic fundamentals. As Obstfeld and Rogoff (2000) argue, this inconsistency of the results with the predictions of the model led many of the researches of this particular SRP to presume that not only those fundamentals do not matter for the exchange rate swings, but also the participants of the market behave irrationally.

On the other hand, Frydman and Goldberg (2007) argue that it is not possible to find only a single set of economic fundamentals that has mattered in a dynamic world economy in the exact same way, since the floating currencies have became the norm in the 1970's. Using this argument, the IKE approach criticizes the REH based models for their expectations to find a single set of economic fundamentals that has mattered in exactly the same way at every point in time for the last forty years.

According to the IKE approach, the exchange-rate-disconnect puzzle disregards important evidence. This approach highlights that while macroeconomic fundamentals matter for exchange-rate movements, the causal mechanism that underpins these movements is temporally unstable. This shows that, not only the coefficients of empirical models change from one sub-period of floating to another, but also these sets of fundamentals that matter for exchange rates also change from time to time. That is why, the IKE approach is capable of taking into account the temporal instability, in contrast to the REH based fully predetermined models that cannot account for such structural changes. Therefore, the nature and timing are able to depend on how market participants revise their forecasting strategies on unforeseeable changes in the social context.

The third problem that the REH based SRPs cannot empirically predict is the forward discount anomaly. Relying on invariant empirical relationships, researchers of this SRP report that future returns in currency markets co-vary negatively with the current value of the forward premium. The forward premium depends on the difference between the forward and spot exchange rates. In the SRP of the contemporary approach, conventional economists try to explain this behavior by constructing exchange rate models in which risk-averse individuals require a positive return. This is also called a premium to hold risky positions in currency markets. However, this approach also does not give successful results. The researches of this SRP are unable to explain the negative co-variation between the return on foreign exchange and the forward premium. Therefore, as Froot (1989) and Obstfeld and Rogoff (1996) point out in their studies, this SRP makes the prediction that one can make predictable profits by betting against the forward rate. It follows then, the question in the international finance literature considers why these profits remain unexploited, which has become one of the major puzzles of this SRP.

There are a couple of known studies in the literature that further investigate this relationship. Taylor (1988), MacDonald and Torrance (1988), Ito (1990), Liu and Madalla(1992) argue that the relationship between the return on foreign exchange and the forward premium is temporally unstable. Roman and Goldberg (2007) present evidence on the investigation and show that the correlation between the return on foreign exchange and the forward premium is actually not stable. Whereas, they identify that this relationship is sometimes negative, sometimes positive, and sometimes insignificantly different from zero.

As a result, imposing temporal instability makes a big distinction on this puzzling behavior. A return process that gives rise to both negative and positive correlations with the forward premium actually show the fact that betting 
against the forward rate will be profitable during some periods of time, and it will not be profitable in others. Because the contemporary approach constructs fully predetermined and mostly invariant models of foreign exchange returns that ignore temporal instability, the SRP of the REH based approaches creates artifacts that are epistemologically flawed in the contemporary approach. Therefore, it can be argued that the sharp assumptions of the REH that is utilized in thousands of studies misdirect the progress of this Lakatosian SRPs.

On the other hand, according to the IKE based models, knowledge is assumed to be imperfect accounting that there is always change in an unmechanical way. Contrary to the REH based models, IKE based models assume that there is always diversity among people in real world. IKE based approaches are able to realize that the world we live actually changes over and over in every second. Besides it accounts for the institutional changes, as well as the changes in the policies and the economic situations. To sum up, the underlying structure of the overall economy changes at every point in time, and this is actually consistent with the reasons that the markets exist in the first place. In that respect, IKE based models consider two types of regularities on the individuals. First, an individual's forecasting strategy at different times may have certain qualitative features in common. Second, although the way that any of the causal variables affecting an individual's forecasting behavior may change through time, these changes may have some certain qualitative features in common. IKE's individual behavior stands on the fact that the model is constructed for the market premium, involve specifications for bulls' and bears' forecasts of the potential loss from holding speculative positions. It uses the Uncertainty adjusted UIP (UAUIP), which is an alternative equilibrium condition for the Foreign Exchange markets, shows that the exchange rate adjusts so as to equate the risk adjusted expected returns on domestic and foreign assets. And therefore, different variables and macroeconomic fundamentals, affect these expectations differently at every point in time.

As a result, it is possible to argue that the predictions of the REH based models are inconsistent with the empirical regularity. There are still hundreds of studies try to use different advanced econometric techniques in order to get the most out of the data available. However, there is no evidence that supports the prediction relationship of the REH based models. From the previous analyses, one can conclude that the SRP that utilizes REH is not empirically progressive in the Lakatosian framework.

On the contrary, considering the SRP of IKE, there is not enough empirical evidence either to support or reject the theoretical prediction (novel fact). Therefore, although the IKE based models generate theoretical novel facts, we cannot say that this theory is progressive in the Lakatosian sense. We can argue that either the REH based models or the IKE based ones are progressive. However, there are new developments especially in nonlinear econometric modeling, which may change this result in favor of the IKE theory in the near future. With the new developments in the use of nonlinear techniques, it is likely to support the theoretical predictions. However, for the REH based exchange rate models, since the assumptions of the approach are already too sharp so they do not let the theory to explain the real life facts, it is not possible to have any evidence that can support a predictive relationship of the theory.

The exchange rate models utilizing REH fail to have success considering the Lakatosian framework. In the Lakatosian analysis, a theory is degenerating if it is not corroborated and the changes in this theory (protective belt) produce no new novel facts. The main reason that economists employing REH still continue working on this particular SPR is that, it generates only one novel fact. This sole novel fact is given by the stick price models. According to this models, since prices are sticky and cannot freely jump in the short run, exchange rate does all the adjusting. Moreover, Lakatos's MSRP view on degenerating programs suggests that one may rationally stick to a degenerating research program until it is overtaken by a rival and even after. Consequently, considering the fact that the IKE theory on the other hand is still not able to give testable results, we cannot expect that the REH based models to be overtaken by its rival, at least for the time being. Considering the new improvements in the nonlinear methods to predict temporal instability, the IKE based exchange rate theories may give testable results about their predictions. As a result, the REH based SPRs can be overtaken by the IKE based exchange rate models in the framework of the Lakatosian analysis.

\section{Concluding Remarks}

Understanding the factors that explain the exchange rate swings has been the major concern in the international finance literature. Conventional models that utilize REH have been frequently tested in the field and have documented poor results. In addition to the REH based models, an alternative model that employs IKE has recently been developed to understand the same concerns about the exchange rate swings. This paper employs the Lakatosian framework to evaluate the main theoretical contributions of these models regarding the exchange rate movements in the international finance literature. 
The study argues that the contemporary exchange rate models that employing the REH, and the other ones utilizing the IKE constitute different Lakatosian SRP protective belts. The paper analyzes whether or not REH and IKE type of exchange rate models are progressive in explaining the fundamental characteristics of the exchange rate swings. First, the study evaluates the novel facts that are associated with each of the protective belts of both of the SRPs. Moreover, it evaluates the empirical evidences of each SRP, which are related to these novel facts. In addition the paper discusses whether or not both of these SRPs are theoretically and empirically progressive. In terms of the IKE based models, however, there is not enough empirical evidence to support its theoretical prediction (novel fact). As a result, although the theory of IKE generates theoretical novel facts, the theory is not progressive in the Lakatosian perspective. Furthermore, the study discusses that the exchange rate models that are based on REH as a SRP is degeneratingas they both are not corroborated, and the changes in its theory (protective belt) produce no new novel facts. According to the Lakatosian view on the degenerating programs, one may rationally stick to a degenerating SRP until it is overtaken by a rival and even after. Considering that the IKE theory is still not able to give testable results, we cannot argue that the REH based models to be overtaken by its Lakatosian SRP rival, at least for the time being. However, considering the promising developments in the non-linear numerical methods, the IKE based exchange rate theories may give testable results about their predictions. Therefore, the REH based SPRs can be overtaken by the IKE based exchange rate models when we consider temporal instability in the framework of the Lakatosian analysis.

\section{References}

Blaug, M. (1975). Kuhn versus Lakatos, or paradigms versus research programmes in the history of economics. History of Political Economy, 7(4), 399-433. http://dx.doi.org/10.1215/00182702-7-4-399

Blaug, M. (1992). The Methodology of Economics: Or How Economists Explain. New York: Press Syndicate of the University of Cambridge. http://dx.doi.org/10.1017/s0266267100001802

Cavusoglu, N., \& Tebaldi, E. (2006). Evaluating Growth Theories and Their Empirical Support: An Assessment of The Convergence Hypothesis. Journal of Economic Methodology, 13(1), 49-75. http://dx.doi.org/10.1080/13501780600566396

Chari, V. V., Kehoe, P. J., \& McGrattan, E. R. (2002). Can sticky price models generate volatile and persistent real exchange rates?. The Review of Economic Studies, 69(3), 533-563. http://dx.doi.org/10.1111/1467-937x.00216

Cross, R. (1982). The Duhem-Quine Thesis, Lakatos and the Appraisal of Theories in Macroeconomics. The Economic Journal, 92(366), 320-40.

Dornbusch, R. (1983). Exchange Rate Risk and the Macroeconomics of Exchange Rate Determination. In R. Hawkins, R. Levich and C. G. Wihlborg (Eds.), The Internationalization of Financial Markets and National Economic Policy (Vol. 3, pp. 3-27). Greenwich, CT: JAI Press.

Engel, C. (1996). The forward discount anomaly and the risk premium: A survey of recent evidence. Journal of empirical finance, 3(2), 123-192. http://dx.doi.org/10.1016/0927-5398(95)00016-x

Evans, G. W., \& Seppo Honkapohja (2005). An Interview with Thomas J. Sargent. Macroeconomic Dynamics, 9, 561-583. http://dx.doi.org/10.1017/s1365100505050042

Frankel, J. A. (1982). In Search of the Exchange-Rate Risk Premium: A Six Currency Test AssumingMean Variance Optimization. Journal of International Money and Finance, 1, 255-74.

Frankel, J. A., \& Kenneth Froot. (1987, March). Using Survey Data to Test Standard Propositions Regarding Exchange Rate Expectations. American Economic Review, 77, 133-53.

Froot, K., \& Jeffrey, A. F. (1989, February). Forward Discount Bias: Is it an Exchange Risk Premium?. Quarterly Journal of Economics, 104, 139-161, reprinted in Jeffrey A. Frankel, (Ed.), On Exchange Rates (1995). Cambridge, MA: The MIT Press.

Frydman, R., \& Goldberg, M. D. (2007). Imperfect Knowledge Economics: Exchange Rates and Risk. Princeton, NJ.: Princeton University Press. http://dx.doi.org/10.1057/eej.2008.41

Frydman, R., \& Goldberg, M. D. (2008). Macroeconomic Theory for a World of Imperfect Knowledge. Capitalism and Society, 3, 3, Article 1. http://dx.doi.org/10.2202/1932-0213.1046

Frydman, R., \& Goldberg, M. D. (2009). Financial Markets and the State: Price Swings, Risk, and the Scope of Regulation. Capitalism and Society, 4, 2, Article 2. http://dx.doi.org/10.2202/1932-0213.1061

Frydman, R., \& Goldberg, M. D. (2011). Beyond Mechanical Markets: Asset Price Swings, Risk, and the Role of the 
State. Princeton, NJ.: Princeton University Press. http://dx.doi.org/10.1111/1475-4932.12082

Frydman, R., Goldberg, M. D., Johansen, S., \& Juselius, K. (2010a). Why REH Bubble Models Do Not Adequately Account for Swings?. mimeo.

Frydman, R., Goldberg, M. D., Johansen, S., \& Juselius, K. (2010b). Imperfect Knowledge and Long Swings in Currency Markets. mimeo.

Hands, D. W. (1993). Popper and Lakatos In Economic Methodology. In U. Maki, B. Gustafsson and C. Knudsen (Eds.), Rationality, Institutions and Economic Methodology (pp. 61-75). London and New York: Routledge.

Hands, D. W. (2001). Reflection without Rules: Economic Methodology and Contemporary Science Theory. Cambridge: Cambridge University Press.

Hausman, D. M. (1994). Kuhn, Lakatos and the Character of Economics. In R.E. Backhouse (Ed.), New Directions in Economic Methodology, Economics as Social Theory series (pp. 195-215). London and New York: Routledge.

Johansen, S., Juselius, K., Frydman, R., \& Goldberg, M. D. (2010). Testing Hypotheses in an I(2) Model with Applications to the Persistent Long Swings in the Dmk/\$ Rate. Journal of Econometrics, 158, 117-129. http://dx.doi.org/10.1016/j.jeconom.2010.03.018

Juselius, K. (2007). The Cointegrated VAR Model: Methodology and Applications. Oxford, UK: Oxford University Press.

Lakatos, I. (1970). Falsification and the Methodology of Scientific Research Programmes. In I. Lakatos and A. Musgrave (Eds.), Criticism and the Growth of Knowledge (pp. 91-196). Cambridge UK: Cambridge University Press.

Lakatos, I. (1971). History of Science and Its Rational Reconstruction. In R.C. Buck and R.S. Cohen (Eds.), Boston Studies in the Philosophy of Science (pp. 91-135). Dordrecht: D. Reidel.

Liu, P. C., \& Maddala, G. S. (1992). Rationality of survey data and tests for market efficiency in the foreign exchange markets. Journal of International Money and Finance, 11(4), 366-381.

Macdonald, R., \& Torrance, T. S. (1988). On Risk, Rationality And Excessive Speculation In The Deutschmark-Us Dollar Exchange Market: Some Evidence Using Survey Data. Oxford Bulletin of Economics and Statistics, 50(2), 107-123.

Obstfeld, C. M., \& Rogoff, K. (2001). The six major puzzles in international macroeconomics: is there a common cause?. In NBER Macroeconomics Annual 2000, Volume 15 (pp. 339-412). MIT Press.

Rogoff, K. (1996). The purchasing power parity puzzle. Journal of Economic Literature, 647-668.

Schmidt, R. H. (1982). Methodology and Finance. Theory and Decision, 14, 391-413.

Taylor, M. P. (1988). An empirical examination of long-run purchasing power parity using cointegration techniques. Applied Economics, 20(10), 1369-1381. 